Volume 8, No.4, July - August 2019

International Journal of Advanced Trends in Computer Science and Engineering

Available Online at http://www.warse.org/IJATCSE/static/pdf/file/ijatcse37842019.pdf

https://doi.org/10.30534/ijatcse/2019/37842019

\title{
An Efficient Approach for Semantic Image Classification using Normalization Method
}

\author{
Sumit Dhariwal ${ }^{1}$, Sellappan Palaniappan ${ }^{2}$ \\ ${ }^{1}$ Department of Information \& Technology, Malaysia University of Science and Technology, Malaysia, \\ sumit.dhariwal@phd.must.edu.my \\ ${ }^{2}$ Department of Information \& Technology, Malaysia University of Science and Technology, Malaysia, \\ sell@ must.edu.my
}

\begin{abstract}
Nowadays Image changes are programmed with the most luminous glow low- resolution symbolism. There is a significant standoff between these receipts. The research was carried out to aid in curbing crime in the future where the novel receipt is proposed for effective correspondence. The method of automating semantic image classification was adapted for this research as well as with various SVM classifiers. It is notified that for the semantic image classification, a normalized method is the best. The study inculcated weight features to calculate kernel function to generalize it. Adding on, to classify new images Trained SVMs were used. The Experimental results based on the 256 categories of the database showed there are some benefits of using SVM with better performance in the normalized image-catering systems during training and generalization. The identity error rate that was discovered in the study is $97 \%$ where there was a decrease of $90 \%$ to $97 \%$. The best performance method-filter, combination-identifying individuals is $98.986 \%$
\end{abstract}

Key words : Semantic Image Classification, CBIR, SVM, NFSVM, RBF, SKF, PKF.

\section{INTRODUCTION}

Large collections of pictures have become offered to the public, from photograph collections to web content or possibly video databases. To index or retrieve them could be a challenge that's the main target of much analysis comes (for instance IBM's QBIC [1]). An oversized a part of this analysis work is dedicated to finding appropriate representations for the photographs, and retrieval typically involves comparisons of pictures. In this paper, we decide to use color histograms as image illustration as a result of the affordable performance, which will be obtained in spite of their extreme simplicity [2]. During this the paper we tend to try to verify a picture completely different feature like Mean of red blue and inexperienced bar chart worth and realize the quality deviation worth of red blue \& image texture energy and entropy, distinction of image, horizontal vertical edge density and horizontal edge density, image center of $x \& y$, realize this class of object that's the foremost doubtless to be conferred in an exceedingly given image. From classification, trees to image classification their area unit several choices for what classifier to use. The Support Vector Machine (SVM) approach is taken into account a decent candidate as a result of its high generalization performance while not the necessity to feature a priority datum, even once the dimension of the input area is incredibly high.

\section{SUPPORT VECTOR MACHINE}

Support vector machine (SVM) is a kind of machine learning algorithm based on the statistical learning the theory that works according to the principle of structural risk minimization (SRM) rather than the empirical risk minimization of large samples. SVM has good generalization performance without the need to add a priori knowledge, even when the dimension of the input space is very high [3]. To be specific, SVM works by mapping the training data into a high dimensional feature space. After that, it separates the two classes of data with a hyperplane and maximizes the distance, which is called the margin. By introducing kernels into the algorithm, it is possible to maximize the margin in the feature space which is equivalent to nonlinear decision boundaries in the original input space. Given that the labeled training examples are $\left(\mathrm{x}_{1}, \mathrm{y}_{1}\right), \ldots,\left(\mathrm{x}_{\mathrm{n}}, \mathrm{y}_{\mathrm{n}}\right)$, where each $\mathrm{x}_{\mathrm{k}} \in \mathrm{R}^{\mathrm{n}}$ is the $\mathrm{k}^{\mathrm{th}}$ input sample and $\mathrm{y}_{\mathrm{k}} \in\{+1,-1\}$ is the $\mathrm{k}^{\text {th }}$ output pattern. In their simplest form, SVM can find out the hyperplane that separates the training data by a maximal margin. All vectors lying on one side of the hyperplane are labeled as -1 , and all vectors lying on the other side is labeled as +1 . The training instances that locate closest to the hyperplane are called support vectors, as a linearly separable binary classification problem. The goal of SVM is to produce a model that predicts the target value of data instances only with the attributes in the testing set. Scientifically, the support vector method can be formulated as follows:

$y(x)=\operatorname{sign}\left(\sum_{k=1}^{n} \alpha_{k} y_{k} \Psi\left(x_{k}, x\right)+b\right)$

Where $\alpha_{\mathrm{k}}$ represents the support value of each sample, $\Psi\left(\mathrm{x}_{\mathrm{k}}\right.$ ,x) denotes the kernel function that satisfies Mercer's condition, and $\mathrm{y}(\mathrm{x})$ stands for the class label predicted by the SVM model. It should be noted that a challenging problem for SVM is the choice of kernel functions, which is actually a measure of similarity between two vectors. Gaussian radial basis function (RBF) and polynomial kernel are two commonly used kernel functions listed as follows: 
$K\left(x_{k}, x\right)_{R B F}=\exp \left(-\gamma\left\|x_{k}-x\right\|^{2}\right), \gamma>0$

$K\left(x_{k}, x\right)_{R B F}=\left[\left(x_{k} \times x\right)+c\right]^{q}$

As for the parameters of SVM, $5 \times 2$ cross-validation and grid-search algorithms usually estimate them respectively. Additionally, since image annotations are not likely to be linearly separable in the projected space, it needs to be allowed for some training errors. This need gives rise to the soft-margin SVM algorithm, which can be formulated as a special case of the hard margin version with the modified kernel by adding a factor to penalize training errors. More details can be gleaned from reference [4].

\subsection{Optimal Separating Hyperplanes}

We give in this section a really temporary introduction to sup- port vectors.

Let the $\left(\mathrm{x}_{\mathrm{i}}, \mathrm{y}_{\mathrm{i}}\right) 1 \leq \mathrm{i} \leq \mathrm{N}$ be a set of preparation(Training) examples, each example $x_{i} \in R^{d}$, $d$ being the dimension of the input space, belongs to a class labeled by $\mathrm{yi}_{\mathrm{i}} \in\{-1,1\}$. The aim is to define a hyperplane, which divides the set of examples such that all the points with the same label are on the same side of the hyperplane. This extents to outcome $w$ and $b$ so that

$$
y_{i}\left(w \cdot x_{i}+b\right)>, i=1, \ldots, N
$$

If there exists a hyperplane satisfying Eq. (1), the set is said to be linearly separable. In this circumstance, it is always probable to re-scale $\mathrm{w}$ and $\mathrm{b}$ so that

$$
\min _{1 \leq i \leq N} y_{i}\left(w . x_{i}+b\right) \geq 1, i=1, \ldots, N
$$

So in that case the neighboring point to the hyperplane has a distance of $1 /\|w\|$. Then, Eq. (1) converts

$$
y_{i}\left(w \cdot x_{i}+b\right) \geq 1
$$

Between the separating hyperplanes, the one for which the distance to the neighboring point is maximal is called optimal separating hyperplane $(\mathrm{OSH})$. Since the distance to the neighboring point is $1 /\|w\|$, finding the OSH amounts to reducing $\|w\|^{2}$ under constraints (2).

The amount of $2 /\|\mathrm{w}\|$ is called the margin, and thus the $\mathrm{OSH}$ is the unscrambling (seprating) hyperplane which increases the margin. The margin can be seen as a amount of the simplification ability: the larger the margin, the better the simplification is expected to be [5], [6].

As $\|w\|^{2}$ is curved, reducing it under linear constraints (2) can be achieved with Lagrange multipliers. If we signify by $\alpha=$ $(\alpha 1, \ldots, \alpha \mathrm{N})$ the $\mathrm{N}$ non negative La- grange multipliers associated with constraints (2), our optimization problem extents to raising

$$
W(\alpha)=\sum_{i=1}^{N} \alpha_{i}-\frac{1}{2} \sum_{i, j=1}^{N} \alpha_{i} \alpha_{j} y_{i} y_{j} x_{i} \cdot x_{j}
$$

with $\alpha_{\mathrm{i}} \geq 0$ and under constraint $\sum_{i=1}^{N} y_{i} \alpha_{i}=0{ }^{\mathrm{N}}$ This can be achieved by the use of standard quadratic programming methods [7]. Once the vector $\alpha^{0}=\left(\alpha_{1}{ }^{0}, \ldots, \alpha_{N}{ }^{0}\right)$ solution of the maximization problem (3) has been found, the $\mathrm{OSH}$ $\left(w_{0}, b_{0}\right)$ has the following expansion

$$
w_{o}=\sum_{i=1}^{N} \alpha_{i}^{0} y_{i} x_{i}
$$

The support vectors are the facts for which $\alpha_{i}{ }^{0}>0$ fulfill Eq. (2) with equality.

Reflecting the increase (4) of w0, the hyperplane decision function can thus be written as.

$$
f(X)=\operatorname{sgn}\left(\sum_{i=1}^{N} \alpha_{i}^{0} y_{i} x_{i} \cdot x+b^{0}\right)
$$

\subsection{Kernel Function Selection}

a) The Radial Basis Function Kernel

The Radial basis function kernel, also called the RBF kernel, or Gaussian kernel, is a kernel that is in the form of a radial basis function (more specifically, a Gaussian function). The RBF kernel is defined as

$$
K_{R B F}\left(x, x^{\prime}\right)=\exp \left[-\gamma\left\|x-x^{\prime}\right\|^{2}\right]
$$

Where $\gamma$ (gama) is a constraint (parameter) that sets the "spread" of the kernel.

The Radial Basis kernel Function as a projection into infinite measurements

Recollection a kernel is any function of the form:

$$
K\left(x, x^{\prime}\right)=\left\langle\psi(x), \psi\left(x^{\prime}\right)\right\rangle
$$

Where $\psi$ is a function that projection vectors $\mathbf{x}$ into a new vector space. The kernel function computes the inner product between two projected vectors.

As we prove below, the $\psi$ function for an RBF kernel projects vectors into an infinite dimensional space. For Euclidean vectors, this space is an infinite dimensional Euclidean space. That is, we prove that

$$
\psi_{R B F}: \mathbb{R}^{n} \rightarrow \mathbb{R}^{\infty}
$$

\section{b) Sigmoidal Kernel Function}

The Hyperbolic Tangent Kernel is also known as the Sigmoid Kernel and as the Multilayer Perceptron (MLP) kernel. The Sigmoidal Kernel comes from the Neural Networks field, where the bipolar sigmoid function is often used as an activation function for artificial neurons.

$$
k(x, y)=\tanh \left(\alpha x^{T}+c\right)
$$

It is interesting to note that an SVM model using a sigmoidal kernel function is equivalent to a 
two-layer, Perceptron neural network. This kernel was quite general for SVM due to its origin from neural network theory. Also, despite being only conditionally positive definite. [8]

c) Polynomial Kernel Function

The Polynomial kernel is defined as

$$
k(\vec{x}, \vec{z})=\left(\vec{z}^{T} \vec{x}+c\right)^{n}
$$

Where $\mathrm{n}$ is the "order" of the kernel, and $\mathrm{c}$ is a constant that allows trading of the influence of the higher-order and lowers order terms. Second-order or quadratic kernels are a general form of PKF (Polynomial kernel Function), widely used in Speech Identification. Higher-order kernels tend to "over-fit" the preparation data, and thus do not simplify well.[9]

\section{LITERATURE REVIEW}

A significant number of the AI strategies have been done on programmed semantic image grouping there are different methodologies for semantic image characterization of pictures based on SVM to arrange the pictures consequently, first, we have to separate the highlights from the preparation informational collection to ascertain the weight $w_{\text {im }}$ for each component. At that point apply the weighted element to prepare the SVM subsequently train SVM to group the new pictures. The informational collection was taken as comprising 1000 pictures. Every classification including 100 pictures speaks to one particular theme of intrigue. In this way, the informational index has 10 specifically differing pictures classifications. Every one of the pictures is in the JPEG group with size $384 \times 256$ or $256 \times 384$. The watchwords are appointed to depict each picture classification. The class names are the sun, food, flower, building, mountain, horse, dinosaur, elephant, beach and bus. What's more, some arbitrarily chosen test pictures from every classification pictures of each class are haphazardly drawn as preparing tests. So 300 pictures are utilized for preparing and the staying 700 are utilized for testing. Each picture is spoken to as a 30-dimensional vector, which compares to 30 low-level highlights, for previously example, shading, shape, size, surface, and position. WF-SVM outflanks the SVM framework by only $16.86 \%$ in the general exactness. [10] Automated weighted SVM for standardization picture order dependent on a picture from the different categories of the database. Taking only 1000 pictures in our informational collection each classification including only 100 pictures speaks to one unmistakable point of intrigue. Along these lines, the informational index has various picture classifications. Every one of the pictures is in the JPEG group with size $384 \times 256$ or $256 \times 384$ using some different categories of images and only 10 pictures of each class are haphazardly drawn as preparing tests are not appropriate. [11] The principal objective of this work is to only improve the utilization of a presenting joined with a picture repositioning in the Multimedia Information Retrieval Function. [12] There are two noteworthy issues with the utilization of nonlinear models: First, they are hypothetically hard to break down, and second, they are computationally hard to unravel. [13] Only
One-Class SVM based MIL structure for a single thing based on CBIR frameworks. [14] The SVM classifier can be gained from preparing information of importance pictures and insignificance pictures set apart by clients. Utilizing the classifier, the framework can recover only limited pictures. [15] The several models' properties which helped us to detect corners on corners. It has been shown that the resolution of only the high corner of the proposed method is used. [16] Earlier, some researchers study based on single or limited image feature content on general-purpose have been attained; however, past literature doesn't provide evidence of image classification. [17] [18]

\section{METHODOLOGY \& EXPERIMENTATION}

In this paper we are proposing a method for improving semantic image classification \& its presentation with the help of support vector machine. It is proposed that in each section of the image deviation and an image feature vector is finally found, so in this research, we used different SVM classifier to implement different image databases and found that by SVM classifier First better-suited results, we reduce the dimensions of an image database, and we create a new bitmap matrix of different image data, and for the support vector threshold values apply and will vary between zero to one and we determine the pixel deviation of an image.

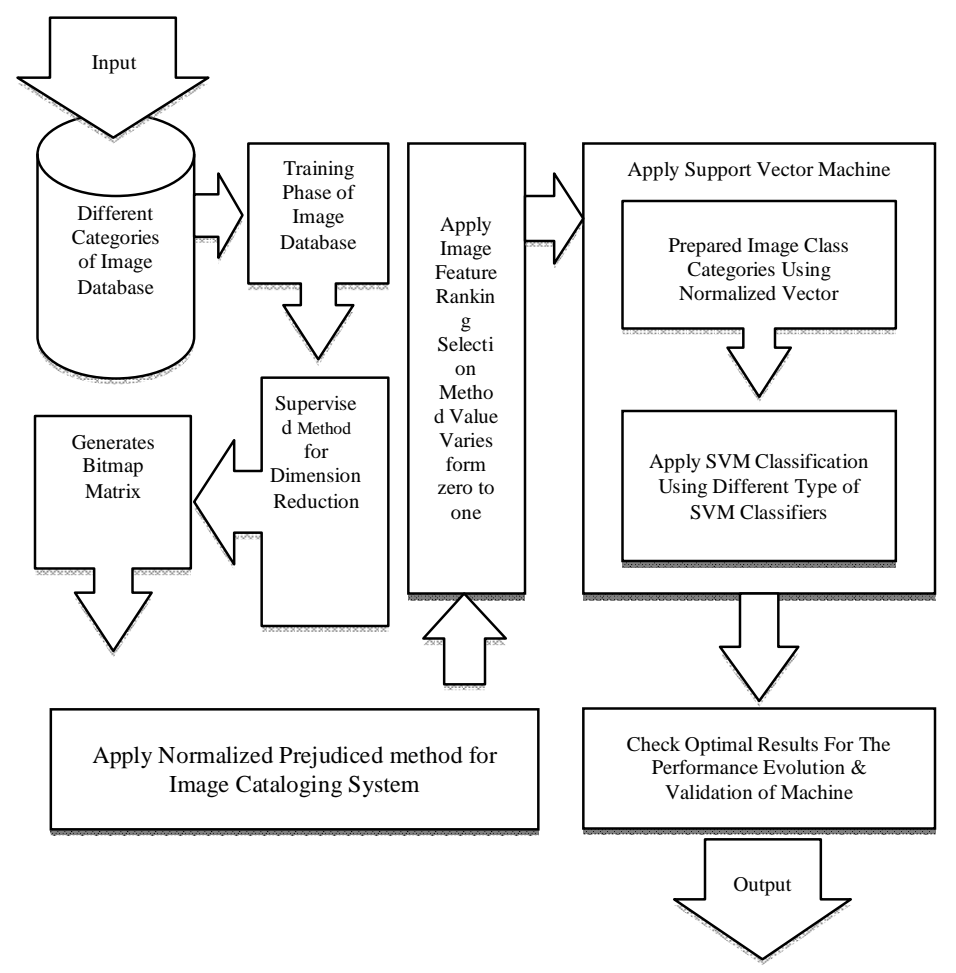

Figure 1: Structure Scheme \& Working Format 


\subsection{Semantic Image Classification's Experiment}

This experiment clearly proves that the Table 1, Table 2, Table 3, results of the proposed system are best \& suitable with different categories of semantic image classification, and overall classification accuracy and the approximate average training time is higher. It visibly shows that our proposed system performs better, and it outperforms the SVM system by $98.95 \%$ in the overall accuracy with RBF kernel function, and polynomial \& sigmoidal-based result is $96.98 \%$ and $97.26 \%$. Our system also improves the training speeded by Five times over the SVM system. Consequently, we experimentally prove that our approach not only improves the overall classification accuracy but also reduces the training time.

The recognizable proof rate can be determined as -

\section{Identification Ratio}

$=[($ Mean of total no. of matches in each categories $)$

* $10-($ Average Precision \% $)]$

Table 1: RBF Kernel Based Testing Recognition System Using SVM

\begin{tabular}{|c|l|l|l|l|l|l|l|l|l|l|}
\hline & $\begin{array}{c}\text { Buddha } \\
\text { Database }\end{array}$ & $\begin{array}{c}\text { Flag } \\
\text { Database }\end{array}$ & $\begin{array}{l}\text { PalmTree } \\
\text { Database }\end{array}$ & $\begin{array}{c}\text { AK47 } \\
\text { Database }\end{array}$ & $\begin{array}{c}\text { Zebra } \\
\text { Database }\end{array}$ & $\begin{array}{c}\text { Anchor } \\
\text { Database }\end{array}$ & $\begin{array}{c}\text { Starfish } \\
\text { Database }\end{array}$ & $\begin{array}{c}\text { Faces } \\
\text { Database }\end{array}$ & $\begin{array}{c}\text { Wildcat } \\
\text { Database }\end{array}$ & $\begin{array}{c}\text { Lotus } \\
\text { Database }\end{array}$ \\
\hline $\begin{array}{c}\text { Buddha } \\
\text { Database }\end{array}$ & 0.9889 & 0.0000 & 0.0111 & 0.0000 & 0.0000 & 0.0000 & 0.0000 & 0.0000 & 0.0000 & 0.0000 \\
\hline $\begin{array}{c}\text { Flag } \\
\text { Database }\end{array}$ & 0.0000 & 0.9892 & 0.0000 & 0.0000 & 0.0108 & 0.0000 & 0.0000 & 0.0000 & 0.0000 & 0.0000 \\
\hline $\begin{array}{c}\text { PalmTree } \\
\text { Database }\end{array}$ & 0.0122 & 0.0000 & 0.9878 & 0.0000 & 0.0000 & 0.0000 & 0.0000 & 0.0000 & 0.0000 & 0.0000 \\
\hline $\begin{array}{c}\text { AK47 } \\
\text { Database }\end{array}$ & 0.0000 & 0.0000 & 0.0000 & 0.9888 & 0.0000 & 0.0000 & 0.0000 & 0.0000 & 0.0112 & 0.0000 \\
\hline $\begin{array}{c}\text { Zebra } \\
\text { Database }\end{array}$ & 0.0000 & 0.0119 & 0.0000 & 0.0000 & 0.9881 & 0.0000 & 0.0000 & 0.0000 & 0.0000 & 0.0000 \\
\hline $\begin{array}{c}\text { Anchor } \\
\text { Database }\end{array}$ & 0.0000 & 0.0000 & 0.0000 & 0.0000 & 0.0000 & 0.9896 & 0.0000 & 0.0104 & 0.0000 & 0.0000 \\
\hline $\begin{array}{c}\text { Starfish } \\
\text { Database }\end{array}$ & 0.0000 & 0.0000 & 0.0000 & 0.0000 & 0.0000 & 0.0000 & 0.9885 & 0.0000 & 0.0115 & 0.0000 \\
\hline $\begin{array}{c}\text { Faces } \\
\text { Database }\end{array}$ & 0.0000 & 0.0000 & 0.0000 & 0.0114 & 0.0000 & 0.0000 & 0.0000 & 0.9886 & 0.0000 & 0.0000 \\
\hline $\begin{array}{c}\text { Wildcat } \\
\text { Database }\end{array}$ & 0.0000 & 0.0000 & 0.0000 & 0.0000 & 0.0000 & 0.0000 & 0.0000 & 0.0128 & 0.9872 & 0.0000 \\
\hline $\begin{array}{c}\text { Lotus } \\
\text { Database }\end{array}$ & 0.0000 & 0.0000 & 0.0000 & 0.0000 & 0.0000 & 0.0011 & 0.0000 & 0.0000 & 0.0000 & 0.9989 \\
\hline
\end{tabular}

Table 2: Polynomial Based Testing to the Recognition System Using SVM

\begin{tabular}{|c|l|l|l|l|l|l|l|l|l|l|}
\hline & $\begin{array}{l}\text { Buddha } \\
\text { Database }\end{array}$ & $\begin{array}{c}\text { Flag } \\
\text { Database }\end{array}$ & $\begin{array}{l}\text { PalmTree } \\
\text { Database }\end{array}$ & $\begin{array}{c}\text { AK47 } \\
\text { Database }\end{array}$ & $\begin{array}{c}\text { Zebra } \\
\text { Database }\end{array}$ & $\begin{array}{c}\text { Anchor } \\
\text { Database }\end{array}$ & $\begin{array}{c}\text { Starfish } \\
\text { Database }\end{array}$ & $\begin{array}{c}\text { Faces } \\
\text { Database }\end{array}$ & $\begin{array}{c}\text { Wildcat } \\
\text { Database }\end{array}$ & $\begin{array}{c}\text { Lotus } \\
\text { Database }\end{array}$ \\
\hline $\begin{array}{c}\text { Buddha } \\
\text { Database }\end{array}$ & 0.9735 & 0.0000 & 0.0265 & 0.0000 & 0.0000 & 0.0000 & 0.0000 & 0.0000 & 0.0000 & 0.0000 \\
\hline $\begin{array}{c}\text { Flag } \\
\text { Database }\end{array}$ & 0.0000 & 0.9716 & 0.0000 & 0.0000 & 0.0284 & 0.0000 & 0.0000 & 0.0000 & 0.0000 & 0.0000 \\
\hline $\begin{array}{c}\text { PalmTree } \\
\text { Database }\end{array}$ & 0.0000 & 0.0000 & 0.9714 & 0.0000 & 0.0000 & 0.0286 & 0.0000 & 0.0000 & 0.0000 & 0.0000 \\
\hline $\begin{array}{c}\text { AK47 } \\
\text { Database }\end{array}$ & 0.0000 & 0.0000 & 0.0000 & 0.9726 & 0.0000 & 0.0000 & 0.0000 & 0.0000 & 0.0274 & 0.0000 \\
\hline $\begin{array}{c}\text { Zebra } \\
\text { Database }\end{array}$ & 0.0000 & 0.0000 & 0.0000 & 0.0000 & 0.9698 & 0.0000 & 0.0000 & 0.0302 & 0.0000 & 0.0000 \\
\hline $\begin{array}{c}\text { Anchor } \\
\text { Database }\end{array}$ & 0.0000 & 0.0000 & 0.0000 & 0.0000 & 0.0000 & 0.9638 & 0.0000 & 0.0362 & 0.0000 & 0.0000 \\
\hline $\begin{array}{c}\text { Starfish } \\
\text { Database }\end{array}$ & 0.0000 & 0.0000 & 0.0000 & 0.0000 & 0.0000 & 0.0000 & 0.9682 & 0.0000 & 0.0318 & 0.0000 \\
\hline $\begin{array}{c}\text { Faces } \\
\text { Database }\end{array}$ & 0.0000 & 0.0000 & 0.0000 & 0.0371 & 0.0000 & 0.0000 & 0.0000 & 0.9629 & 0.0000 & 0.0000 \\
\hline $\begin{array}{c}\text { Wildcat } \\
\text { Database }\end{array}$ & 0.0000 & 0.0000 & 0.0000 & 0.0000 & 0.0000 & 0.0000 & 0.0000 & 0.0276 & 0.9724 & 0.0000 \\
\hline $\begin{array}{c}\text { Lotus } \\
\text { Database }\end{array}$ & 0.0000 & 0.0000 & 0.0000 & 0.0000 & 0.0000 & 0.0282 & 0.0000 & 0.0000 & 0.0000 & 0.9718 \\
\hline
\end{tabular}


Table 3: Sigmoidal Based Testing the Recognition System Using SVM

\begin{tabular}{|c|l|l|l|l|l|l|l|l|l|l|}
\hline & $\begin{array}{c}\text { Buddha } \\
\text { Database }\end{array}$ & $\begin{array}{c}\text { Flag } \\
\text { Database }\end{array}$ & $\begin{array}{c}\text { Palm } \\
\text { Tree } \\
\text { Database }\end{array}$ & $\begin{array}{c}\text { AK47 } \\
\text { Database }\end{array}$ & $\begin{array}{c}\text { Zebra } \\
\text { Database }\end{array}$ & $\begin{array}{c}\text { Anchor } \\
\text { Database }\end{array}$ & $\begin{array}{c}\text { Starfish } \\
\text { Database }\end{array}$ & $\begin{array}{c}\text { Faces } \\
\text { Database }\end{array}$ & $\begin{array}{c}\text { Wildcat } \\
\text { Database }\end{array}$ & $\begin{array}{c}\text { Lotus } \\
\text { Database }\end{array}$ \\
\hline $\begin{array}{c}\text { Buddha } \\
\text { Database }\end{array}$ & 0.9528 & 0.0000 & 0.0472 & 0.0000 & 0.0000 & 0.0000 & 0.0000 & 0.0000 & 0.0000 & 0.0000 \\
\hline $\begin{array}{c}\text { Flag } \\
\text { Database }\end{array}$ & 0.0000 & 0.9589 & 0.0000 & 0.0000 & 0.0411 & 0.0000 & 0.0000 & 0.0000 & 0.0000 & 0.0000 \\
\hline $\begin{array}{c}\text { PalmTree } \\
\text { Database }\end{array}$ & 0.0422 & 0.0000 & 0.9578 & 0.0000 & 0.0000 & 0.0000 & 0.0000 & 0.0000 & 0.0000 & 0.0000 \\
\hline $\begin{array}{c}\text { AK47 } \\
\text { Database }\end{array}$ & 0.0000 & 0.0000 & 0.0000 & 0.9564 & 0.0000 & 0.0000 & 0.0000 & 0.0000 & 0.0436 & 0.0000 \\
\hline $\begin{array}{c}\text { Zebra } \\
\text { Database }\end{array}$ & 0.0000 & 0.0452 & 0.0000 & 0.0000 & 0.9548 & 0.0000 & 0.0000 & 0.0000 & 0.0000 & 0.0000 \\
\hline $\begin{array}{c}\text { Anchor } \\
\text { Database }\end{array}$ & 0.0000 & 0.0000 & 0.0000 & 0.0000 & 0.0000 & 0.9532 & 0.0000 & 0.0468 & 0.0000 & 0.0000 \\
\hline $\begin{array}{c}\text { Starfish } \\
\text { Database }\end{array}$ & 0.0000 & 0.0000 & 0.0000 & 0.0000 & 0.0000 & 0.0000 & 0.9537 & 0.0000 & 0.0463 & 0.0000 \\
\hline $\begin{array}{c}\text { Faces } \\
\text { Database }\end{array}$ & 0.0000 & 0.0000 & 0.0000 & 0.0479 & 0.0000 & 0.0000 & 0.0000 & 0.9521 & 0.0000 & 0.0000 \\
\hline $\begin{array}{c}\text { Wildcat } \\
\text { Database }\end{array}$ & 0.0000 & 0.0000 & 0.0000 & 0.0000 & 0.0000 & 0.0000 & 0.0000 & 0.0482 & 0.9518 & 0.0000 \\
\hline $\begin{array}{c}\text { Lotus } \\
\text { Database }\end{array}$ & 0.0000 & 0.0000 & 0.0000 & 0.0000 & 0.0000 & 0.0464 & 0.0000 & 0.0000 & 0.0000 & 0.9536 \\
\hline
\end{tabular}

\section{RESULTS AND DISCUSSIONS}

In this paper, we have shown that it has overcome the $97 \%$ error rate for classification of 10 coral categories and at the same time, it is possible to push the classification performance obtained on semantic image classification to surprisingly high levels. And we prepare our program using the generalized normalized feature and at the same time, the database, which has been taken, is considered as an optimal result, but here this research with the database of two fifty-six categories and different classes. There is a good result using which no one has been done here. Here I have divided 10,000 images into ten classes. Which is used for the classification is taken for training 3,000 images and 7,000 images for classification. In this paper, 10 different type's categories of images have been taken for optimal classification, and From the three pictures shown below, the first ${ }^{1}$ image shows the query image in which we can select the image of the database. The second ${ }^{2}$ image shows that the image selected is converted to a normalized image with the help of the normalization method. And the third $^{3}$ Image (significant set of image) shows the best optimal result.

Categories 1: Buddha

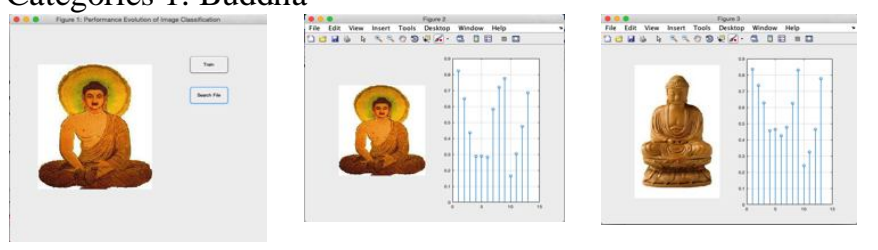

(1)

(2)

(3)

Categories 2: Flag

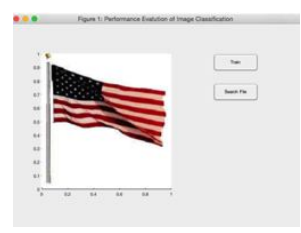

(1)

Categories 3: Faces

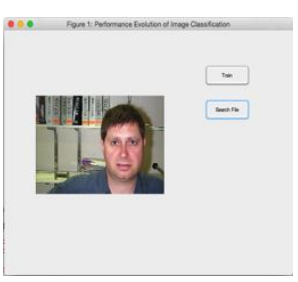

(1)

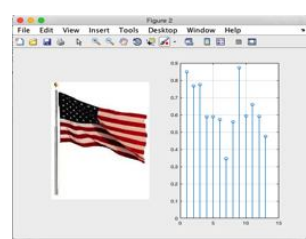

(2)

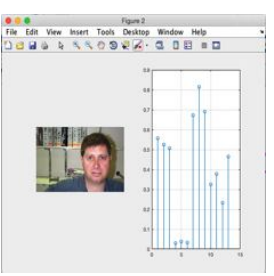

(2)

Categories 4: AK47

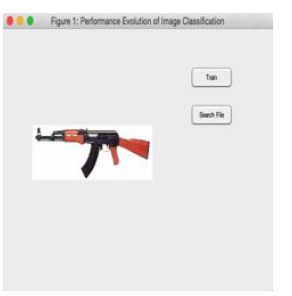

(1)

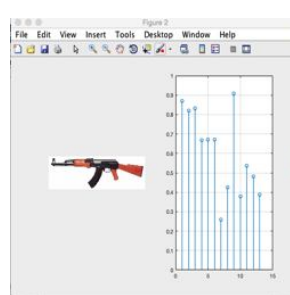

(2)

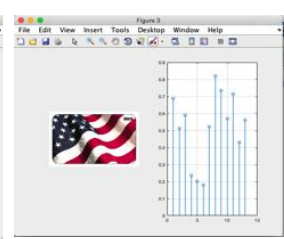

(3)

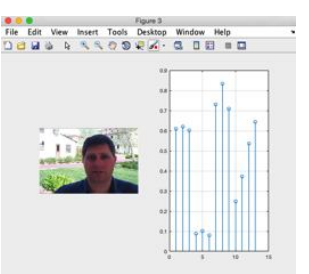

(3)

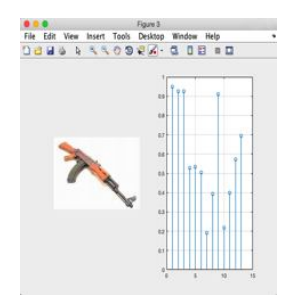

(3) 
Categories 5: Tree(Palmtree)

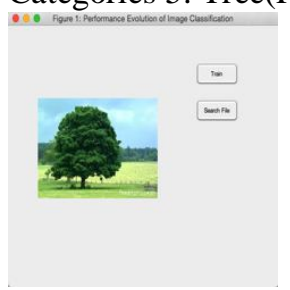

(1)

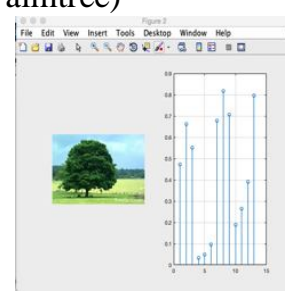

(2)

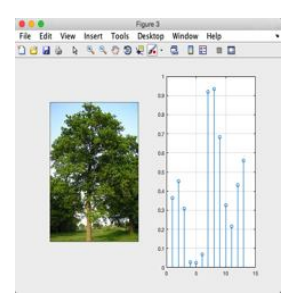

(3)

Categories 6: Horse (Zebra)

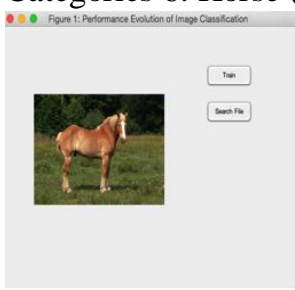

(1)

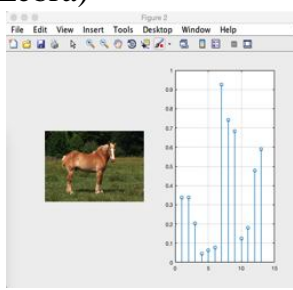

(2)

Categories 7 : Anchor

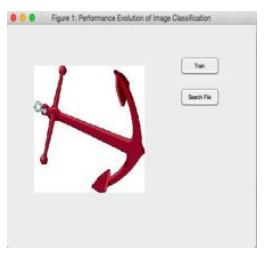

(1)

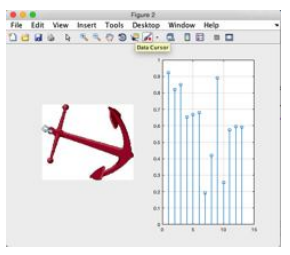

(2)

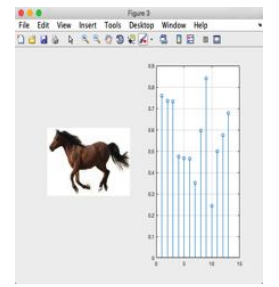

(3)

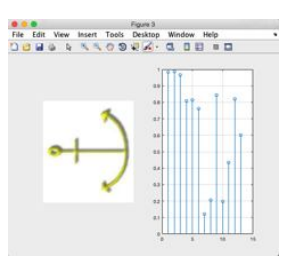

(3)
Categories 8: Starfish

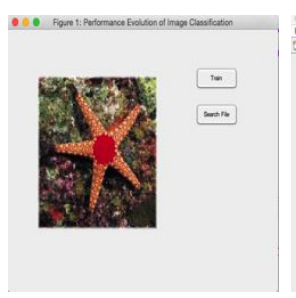

(1)

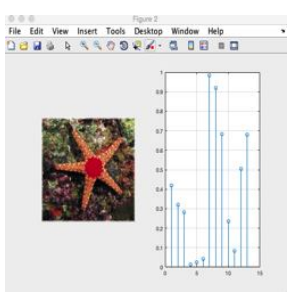

(2)

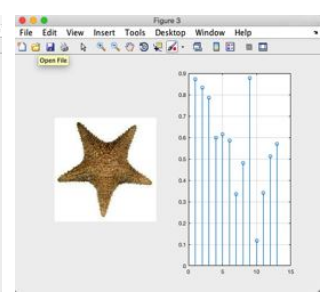

(3)
Categories 9: Wildcat

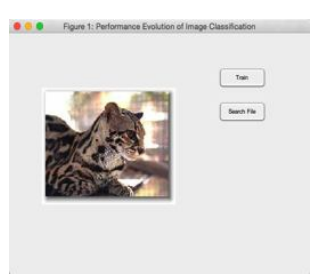

(1)

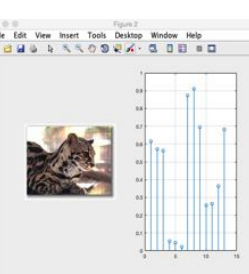

(2)

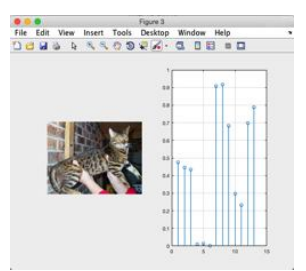

(3)

Categories 10: Rose

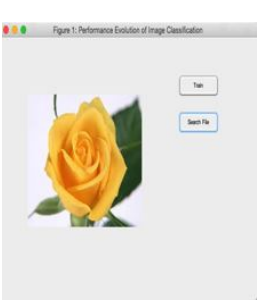

(1)

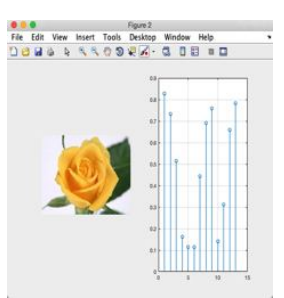

(2)

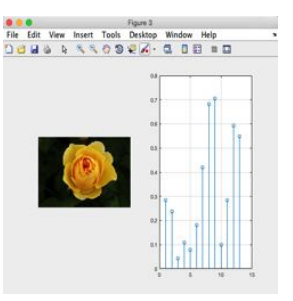

(3)

\section{CONCLUSION}

This paper wonderful performance is due to the superior generalization ability of Support Vector Machines (SVMs) in high dimensional spaces to the use of the normalization method and heavy-tailed Radial Basis Function (RBFs), Sigmoidal and Polynomial as kernels and to nonlinear transformations applied to the feature vector values for image classification. We studied \& used in an RBF, Sigmoidal \& Polynomial kernel affects performance on semantic image classification and found vector values of the kernel function semantic values, we used exponentiation with ranging from 0 downs to 1 . In the case of that kernel is to improve performance similar effects, and their combined influence yields the best performance. This work can be extended in several ways. Higher-level spatial features can be added to the semantic image classification features. Allowing for the detection of multiple objects in a single image would make this classification-based technique usable for image retrieval. It will also be interesting to investigate further what different types of kernels bring to performance and efficiency of recognition rate. This methodology is far higher performance than the standard methodology of image retrieval.

\section{ABBREVIATIONS}

\begin{tabular}{|l|l|}
\hline CBIR & Content based image retrieval \\
\hline SVM & Support vector machine \\
\hline NFSVM & Normalized feature support vector machine \\
\hline AI & Artificial intelligence \\
\hline JPEG & Joint picture expert group \\
\hline SKF & Sigmoidal kernel function \\
\hline PKF & Polynomial kernel function. \\
\hline
\end{tabular}

\section{ACKNOWLEDGEMENTS}

The authors great fully acknowledge helpful comment and valuable discussion with Dr. Sellappan Palaniappan , research analysis performed was at the Malaysia University of Science \& Technology, Malaysia.

\section{REFERENCES}

1. W. Niblack, R. Barber, W. Equitz, M. Flickner, D. Glasman, D. Petkovic, and P. Yanker. The qbic project: Querying image by content using color, texture, and shape, SPIE, vol. 1908, pp. 173-187, February 1993 https://doi.org/10.1117/12.143648

2. M. Swain and D. Ballard. Indexing via color histograms, International Journal of Computer Vision, vol. 7, pp. 11-32, 1991. https://doi.org/10.1007/BF00130487

3. S. Bernhard and J. Alexander. Learning with kernels-support vector machines, regularization, optimization and beyond, 1st ed. The MIT Press, Cambridge, Massachusetts, 2001, ch.3, pp. 405-410.

4. C. Cortes and V. Vapnik. Support vector networks, Machine Learning, vol. 20, no. 3, pp. 1- 25, September 1995.

https://doi.org/10.1007/BF00994018 
5. V. Vapnik. Statistical Learning Theory, 1st ed. John Wiley, New York, $\square$ 1998. ch.10, pp.434-437.

6. P. Bartlett and J. S. Taylor. Generalization performance of support vector machines and other pattern classifiers, Advances in Kernel Methods Support Vector Learning. MIT Press - Cambridge, USA, 1998, ch.2, pp. $2-4$.

7. S. Dhariwal and S. Palaniappan. A New Way of Grace Assortment using Normalized Feature Value by Support Vector. European Journal of Scientific Research, Vol. 151(2), pp. 197-204, December 2018.

8. On-Line Prediction Wiki Contributors. "Kernel Methods." On-Line PredictionWiki. http://onlineprediction.net/?n=Main.Ker nelMethods (March 3, 2010).

9. James L. Crowley "Intelligent Systems: Reasoning and Recognition," Kernel Functions and Support Vector Machines, $\quad 17 \quad$ February 2016. http://www-prima.imag.fr/Prima/Homepages/jlc/Course s/2015/ENSI2.SIRR/ENSI2.SIRR.S5.pdf

10. K.Wang, X.Wang, and Y. Zhong. (2010). A Weighted Feature Support Vector Machines Method for Semantic Image Classification, International Conference on Measuring Technology and Mechatronics Automation. Changsha City, China. 978-0-7695-3962-1/10

11. S. Dhariwal, S. Raghuwanshi and S. Shrivastava. Content Based Image Cataloging Using Normalization Of Vector Approch to SVM, Advances in Computer Science, Engineering \& Applications Advances in Intelligent Systems and Computing. Berlin, Heidelberg, 2012, Vol. 167.

https://doi.org/10.1007/978-3-642-30111-7_76

12. X. Benavent,S. Ana. Garcia, R. Grandos, J. Benavent and E. D. Ves. Multimedia Information Retrieval Based on Late Semantic Fusion Approaches Experiments on a Wikipedia Image Collection, IEEE Transactions on multimedia, Vol. 5(8). pp.1520-9210, June 2013.

13. N. Cristianini and J.S. Taylor. An introduction to support Vector Machines and other kernel-based learning methods, Book Review, New York, Cambridge University Press, 2001, Vol.22, pp.103-104.

https://doi.org/10.1017/CBO9780511801389

14. C. Zhang, X. Chen, M. Chen, S.C. Chen and M.L. Shyu. A Multiple Instance Learning Approach for Content Based Image Retrieval Using One-Class Support Vector Machine, IEEE International Conference on Multimedia and Expo. Amsterdam, Netherlands, July. 2005, pp. 0-7803-9331-7.

15. L. Zhang, F. Lin and B. Zhang. Support vector machine learning for image retrieval, Proceedings 2001 International Conference on Image Processing. Thessaloniki, Greece. August. 2002, pp.0-7803-6725-1.

16. W. Zhang, C. Sun, T. Breckon and N. Alshammari. Discrete Curvature Representations for Noise Robust Image Corner Detection, IEEE Transaction on Image Processing, Vol. 28(9), pp. 4444 - 4459, April 2019. https://doi.org/10.1109/TIP.2019.2910655

17. P. Hong, Q. Tian and T.S. Huang. Incorporate support vector machine to content based image retrieval with $\square$ relevance feedback. International Conference on Image Processing. Vancouver, Canada, August. 2002, pp.1522-4880.

18. G. Carneiro, A.B. Chan, P. J. Moreno and N. Vasconcelos. Supervised learning of semantic classes $\square$ for image annotation and retrieval. IEEE Transactions on Pattern Analysis and Machine Intelligence, Vol. 29 (3), pp. 394 - 410, Jan 2007. 